\title{
Hypoxia-inducible factor-2 $\alpha$ regulates Fas-mediated chondrocyte apoptosis during osteoarthritic cartilage destruction
}

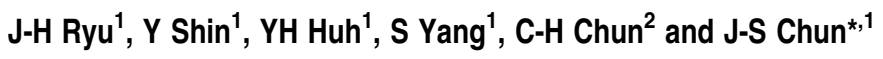

\begin{abstract}
Apoptosis of articular chondrocytes is associated with the pathogenesis of osteoarthritis (OA). Recently, we demonstrated that hypoxia-inducible factor (HIF)-2 $\alpha$, encoded by Epas1, causes OA cartilage destruction by regulating the expression of various matrix-degrading enzymes. Here, we investigated the involvement of HIF-2 $\alpha$ in chondrocyte apoptosis and OA cartilage destruction. HIF-2 $\alpha$ levels in human and mouse OA chondrocytes were markedly elevated in association with increased apoptosis of articular chondrocytes. Overexpression or knockdown of HIF-2 $\alpha$ alone did not cause chondrocyte apoptosis. However, HIF-2 $\alpha$ expression markedly increased chondrocyte apoptosis in the presence of an agonistic anti-Fas (CD95) antibody. HIF-2 $\alpha$ enhanced Fas expression and potentiated downstream signaling pathways, increasing the activity of initiator and executioner caspases. Overexpression of HIF-2 $\alpha$ in mouse cartilage tissue, either by intra-articular injection of Epas1 adenovirus (Ad-Epas1) or in the context of chondrocyte-specific Epas1 transgenic mice, increased chondrocyte apoptosis and cartilage destruction. In contrast, chondrocyte-specific knockout of Epas1 in mice suppressed DMM (destabilization of the medial meniscus)-induced chondrocyte apoptosis and inhibited OA cartilage destruction. Moreover, Fas-deficient mice exhibited diminished chondrocyte apoptosis and OA cartilage destruction in response to Ad-Epas1 injection or DMM surgery. Taken together, our results demonstrate that HIF-2 $\alpha$ potentiates Fas-mediated chondrocyte apoptosis, which is associated with $O A$ cartilage destruction.
\end{abstract}

Cell Death and Differentiation (2012) 19, 440-450; doi:10.1038/cdd.2011.111; published online 26 August 2011

Osteoarthritis (OA) is a degenerative disease characterized by destruction of articular cartilage. The chondrocyte is a unique cell type in articular cartilage that is responsible for cartilage homeostasis and $\mathrm{OA}$ pathogenesis. A variety of potential OA-causing mechanisms have been proposed, including those involving biophysical influences and biochemical factors. ${ }^{1,2}$ OA pathogenesis is associated with inflammatory responses, a reduced ability of chondrocytes to produce extracellular matrix, and degradation of extracellular matrix molecules by catabolic matrix-degrading enzymes. ${ }^{1,2}$ Apoptosis of chondrocytes and the consequent reduction in tissue cellularity are also involved in the pathogenesis of OA. ${ }^{3,4}$ Increased apoptosis of chondrocytes is correlated with the severity of human OA cartilage damage. ${ }^{5,6}$ Apoptotic chondrocytes are found more frequently in cartilage lesions than in non-lesional areas, ${ }^{7}$ and cartilage regions containing apoptotic chondrocytes show proteoglycan depletion. ${ }^{8}$ However, the precise functional relationship between OA and chondrocyte apoptosis is not yet clearly understood. Chondrocytes undergo apoptosis in response to a number of stimuli, including serum starvation, Fas ligand (FasL) or anti-Fas antibody, and nitric oxide donors. ${ }^{3,4}$ Fas (CD95), a member of the tumor necrosis factor receptor family, is a death domain-containing receptor that activates apoptosis signaling. Binding of FasL or agonistic anti-Fas antibody to the Fas receptor triggers apoptotic signals., Although the role of Fas in chondrocyte apoptosis is controversial, ${ }^{9}$ many lines of evidence support such an association. ${ }^{3,4}$ For instance, Fas expression is elevated in OA cartilage compared with normal cartilage. ${ }^{10,11}$ In human cartilage, Fas expression is higher in close proximity to OA lesions than in regions distal to the lesion. ${ }^{7}$ Fas levels are also reported to be higher in aged cartilage, and are correlated with the decreased cellularity in rabbit articular cartilage during aging. ${ }^{12,13}$ Additionally, a significant amount of soluble FasL is found in the synovial fluid of OA patients, ${ }^{14}$ although it is the membrane-bound form of Fas that is associated with apoptotic cell death. Collectively, these observations suggest that Fas and its ligand are physiologically involved in chondrocyte apoptosis.

Recently, we demonstrated that the transcription factor hypoxia-inducible factor (HIF)-2 $\alpha$, encoded by Epas 1 , is a catabolic regulator of cartilage destruction that acts by regulating the expression of various catabolic factors, including matrix-degrading enzymes and inflammation mediators. ${ }^{15}$ In these previous studies, we found that HIF- $2 \alpha$ expression

${ }^{1}$ Cell Dynamics Research Center and School of Life Sciences, Gwangju Institute of Science and Technology, Gwangju, Korea and ${ }^{2}$ Department of Orthopedic Surgery, Wonkwang University School of Medicine, Iksan, Korea

*Corresponding author: J-S Chun, Cell Dynamics Research Center and School of Life Sciences, Gwangju Institute of Science and Technology, Oryon-Dong 1, Buk-Gu, Gwangju 500-712, Korea. Tel: + 8262715 2497; Fax: + 8262715 3304; E-mail: jschun@ gist.ac.kr

Keywords: chondrocytes; apoptosis; Fas signaling; HIF-2 $\alpha$; osteoarthritis

Abbreviations: Ad-Epas1, adenovirus-Epas1; CKO, conditional knockout; DMM, destabilization of the medial meniscus; FACS, fluorescence-activated cell sorting; FasL, Fas ligand; HIF-2 $\alpha$, hypoxia-inducible factor-2 $\alpha$; IL1 $\beta$, interleukin- $1 \beta$; KO mouse, knockout mouse; MMP, matrix metalloproteinase; OA, osteoarthritis; PARP, poly-(ADP-ribose) polymerase; TG, transgenic; TUNEL, TdT-mediated dUTP nick end-labeling; WT, wild-type

Received 01.2.11; revised 18.7.11; accepted 22.7.11; Edited by P Bouillet; published online 26.8.11 
was upregulated by pro-inflammatory cytokines, such as interleukin-1 $\beta$ (IL1 $\beta)$. Its expression was also markedly increased in human and mouse OA cartilage. Moreover, intra-articular injection of an Epas1-expressing adenovirus (Ad-Epas1) triggered articular cartilage destruction in mice and rabbits. Chondrocyte-specific Epas1 transgenic (TG) mice displayed spontaneous cartilage destruction, whereas Epas 1 knockdown in mice (Epas $1^{+/-}$) suppressed cartilage destruction caused by destabilization of the medial meniscus (DMM). ${ }^{15}$ Although it is evident that HIF-2 $\alpha$ is a catabolic regulator of $\mathrm{OA}$ cartilage destruction, it is not known whether HIF- $2 \alpha$ regulates chondrocyte apoptosis in OA cartilage. Therefore, we investigated the function of HIF- $2 \alpha$ in chondrocyte apoptosis and evaluated its link to cartilage destruction. For this purpose, we first examined the role of HIF- $2 \alpha$ in the apoptosis of primary cultured mouse articular chondrocyte caused by anti-Fas antibody, which mimics FasL. As this in vitro system may not represent the in vivo situation, we evaluated HIF-2 $\alpha$ function in Fas-induced chondrocyte apoptosis, and its possible link to OA cartilage destruction in vivo using human OA cartilage and various mouse models of $O A$ cartilage, namely STR/ort, DMM surgery, Ad-Epas 1 injection, and chondrocyte-specific Epas1 TG mice. We additionally used HIF- $2 \alpha-$ and Fas-deficient mouse models. Here we report that HIF-2 $\alpha$ potentiates Fas-mediated chondrocyte apoptosis by upregulating Fas expression and amplifying Fas-induced apoptotic signaling in chondrocytes.

\section{Results}

Chondrocyte apoptosis in human and mouse OA cartilage. We first examined chondrocyte apoptosis in human $\mathrm{OA}$ and experimental mouse $\mathrm{OA}$ cartilage to determine the correlation between HIF- $2 \alpha$ expression and chondrocyte apoptosis during $\mathrm{OA}$ cartilage destruction. Apoptosis was assayed in cartilage tissue sections using TdT-mediated dUTP nick end-labeling (TUNEL) assays. Cartilage destruction was evaluated by alcian blue staining. TUNEL assays revealed a significant increase in the number of apoptotic chondrocytes in association with increased HIF$2 \alpha$ expression in OA-affected (damaged) human cartilage compared with normal and undamaged regions of $\mathrm{OA}$ cartilage (Figure 1a). Chondrocyte apoptosis was also examined in STR/ort mice, which are genetically predisposed to develop OA-like lesions in the medial tibial cartilage. $^{16}$ STR/ort mice at 28 weeks of age showed increased HIF- $2 \alpha$ expression and cartilage destruction compared with CBA control mice. OA cartilage in STR/ort mice also showed a marked increase in the number of TUNEL-positive apoptotic chondrocytes (Figure 1b). Finally, we induced cartilage destruction in mice using the DMM surgical model. ${ }^{15,17}$ Compared with a sham operation, DMM surgery increased HIF-2 $\alpha$ expression and articular cartilage damage in association with an increase in chondrocyte apoptosis (Figure 1c). Thus, all examined OA cartilage showed increased HIF-2 $\alpha$ expression and chondrocyte apoptosis, suggesting a possible association between HIF- $2 \alpha$ expression and chondrocyte apoptosis.

HIF-2 $\alpha$ stimulates anti-Fas antibody-induced apoptosis of articular chondrocytes. Next, we examined the role of HIF- $2 \alpha$ in apoptosis using primary cultures of mouse articular chondrocytes. Neither overexpression of HIF- $2 \alpha$ by Ad-Epas 1 nor stimulation with IL $1 \beta$ caused chondrocyte a
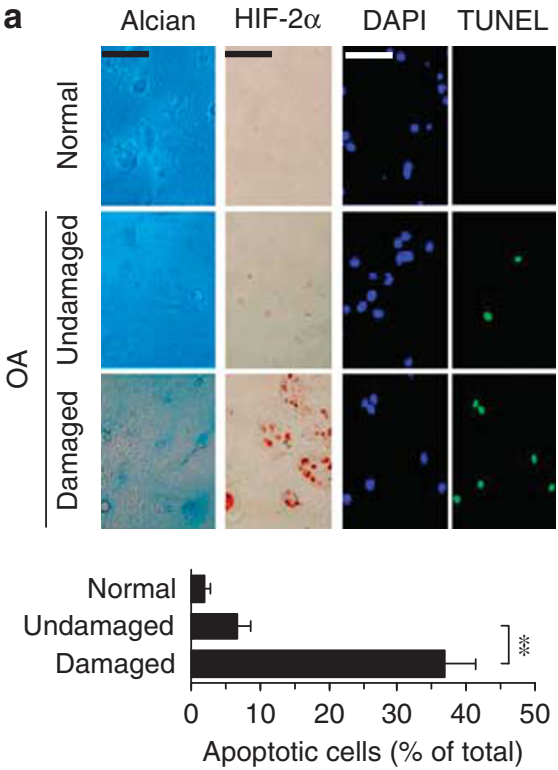

b Safranin O HIF-2 $\alpha$
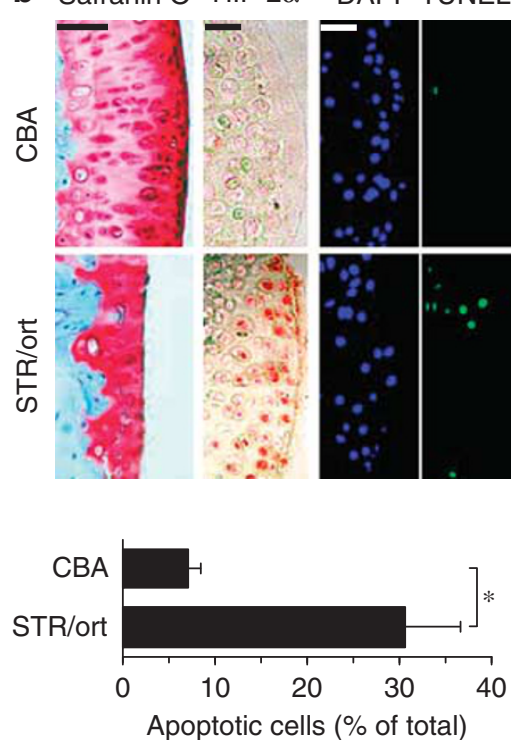
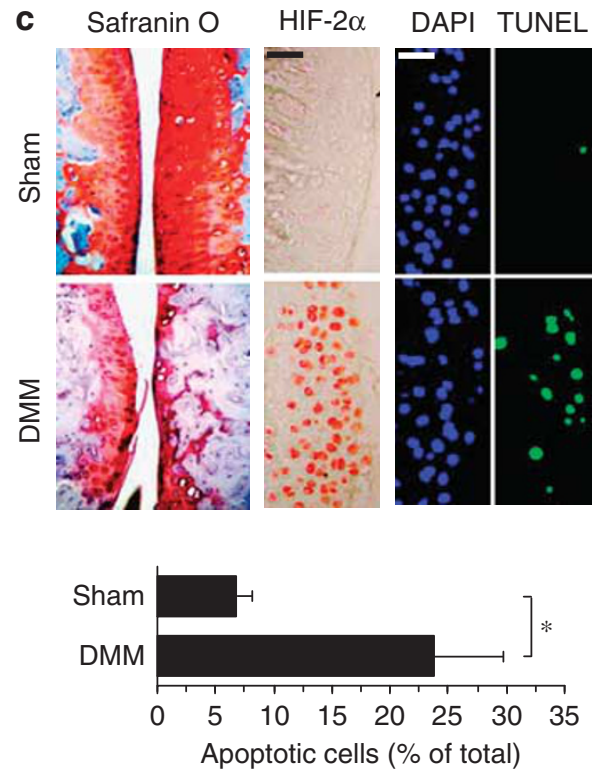

Figure 1 Chondrocyte apoptosis in human and mouse OA cartilage. (a) Sulfate proteoglycan and HIF-2 $\alpha$ protein were detected by alcian blue and immunohistochemical staining, respectively, in normal cartilage, undamaged regions of OA cartilage, and OA-affected (damaged) human cartilage regions. Apoptotic chondrocytes were identified and quantified by TUNEL staining $(n>7)$. (b) Cartilage destruction in 28-week-old STR/ort mice and control CBA mice was visualized by safranin $O$ staining. HIF-2 $\alpha$ protein was detected by immunostaining. Apoptotic chondrocytes were detected and quantified by TUNEL assay $(n>6)$. (c) Cartilage destruction was determined by safranin $\mathrm{O}$ staining of knee joint cartilage after sham operation or DMM surgery. HIF- $2 \alpha$ was detected by immunostaining. Apoptotic chondrocytes were detected and quantified by TUNEL assay $(n>10)$. Values for apoptotic cells are presented as means \pm S.E.Ms. ${ }^{\star} P<0.01$ and ${ }^{*} P<0.001$. Scale bar: $50 \mu \mathrm{m}$ 

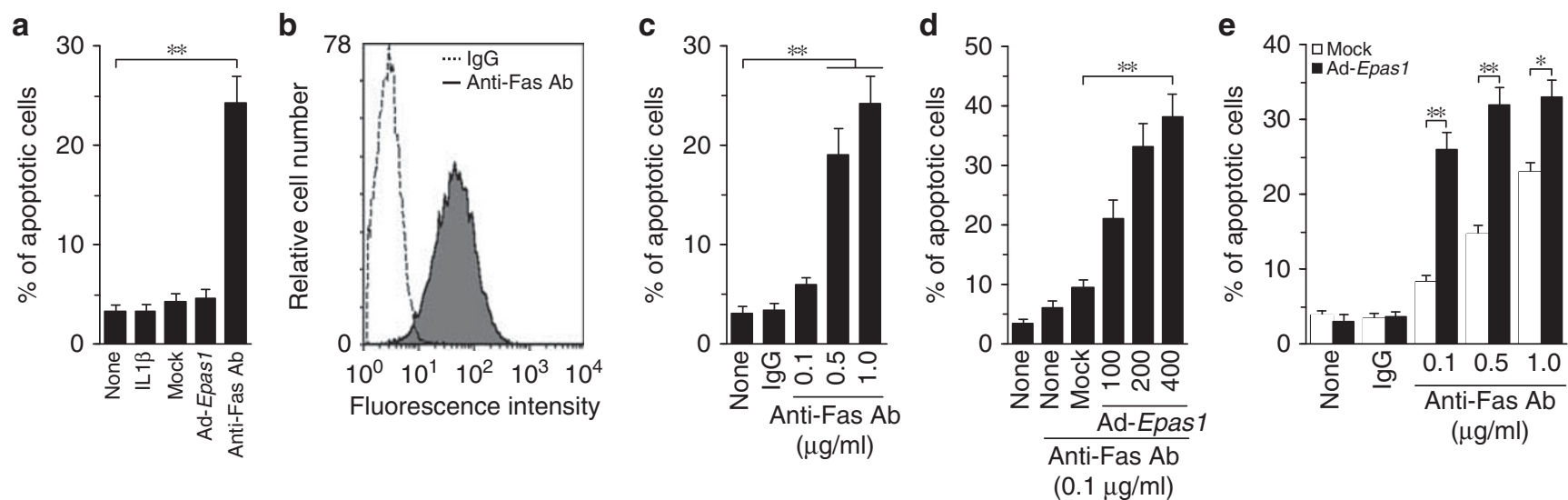

Figure 2 HIF-2 $\alpha$ stimulates anti-Fas antibody-induced chondrocytes apoptosis. (a) Primary cultured mouse articular chondrocytes were untreated, treated with IL1 $\beta$ $(2 \mathrm{ng} / \mathrm{ml})$, or infected at a multiplicity of infection (MOI) of 400 with empty Ad (Mock) or Ad-Epas 1 for $24 \mathrm{~h}$. Alternatively, cells were treated with anti-Fas antibody (1 $\mu \mathrm{g} / \mathrm{ml})$ for $6 \mathrm{~h}$. Apoptotic chondrocytes were quantified by FACS analysis. (b) Surface expression of Fas in articular chondrocytes was determined by FACS analysis. (c) Articular chondrocytes were treated with $\operatorname{lgG}(1 \mu \mathrm{g} / \mathrm{ml})$ or anti-Fas antibody for $6 \mathrm{~h}$, and apoptotic chondrocytes were quantified by FACS analysis. (d) Chondrocytes were infected with empty Ad (Mock; $400 \mathrm{MOI}$ ) or Ad-Epas1 (at the indicated MOls) for $24 \mathrm{~h}$. The cells were incubated with anti-Fas antibody for an additional $6 \mathrm{~h}$, and apoptotic chondrocytes were quantified. (e) Chondrocytes were infected with empty Ad (Mock) or Ad-Epas1 at an MOI of 400 for $24 \mathrm{~h}$. The cells were treated with $\mathrm{lgG}(1 \mu \mathrm{g} / \mathrm{ml})$ or anti-Fas antibody for $6 \mathrm{~h}$, and apoptotic chondrocytes were quantified. Values in $\mathbf{a}, \mathbf{c}$, $\mathbf{d}$, and $\mathbf{e}$ are presented as means \pm S.E.Ms. $(n>10) .{ }^{*} P<0.001$ and ${ }^{* *} P<0.0005$

apoptosis. However, stimulation of the Fas receptor with an agonistic anti-Fas antibody caused chondrocyte apoptosis (Figure 2a and Supplementary Figure 1a). Mouse articular chondrocytes expressed Fas on the cell surface, as determined by fluorescence-activated cell sorting (FACS) analysis (Figure 2b) and confocal microscopy (Supplementary Figure 2). Anti-Fas antibody-induced chondrocyte apoptosis was concentration-dependent: a low concentration of antibody $(0.1 \mu \mathrm{g} / \mathrm{ml})$ did not cause significant apoptosis, but higher concentrations $(0.5$ and $1 \mu \mathrm{g} / \mathrm{ml}$ ) did (Figure $2 \mathrm{c}$ and Supplementary Figure 1b). Although ectopic expression of HIF- $2 \alpha$ alone did not cause chondrocyte apoptosis, overexpression of HIF- $2 \alpha$ in the presence of a low concentration $(0.1 \mu \mathrm{g} / \mathrm{ml})$ of anti-Fas antibody caused a dramatic increase in chondrocyte apoptosis (Figure 2d and Supplementary Figure 1c). HIF-2 $\alpha$ expression also enhanced chondrocyte apoptosis at high antibody concentrations $(0.5 \mu \mathrm{g} / \mathrm{ml}$ and $1 \mu \mathrm{g} / \mathrm{ml}$; Figure $2 \mathrm{e}$ and Supplementary Figure $1 \mathrm{~d})$. Both the apoptotic death of chondrocytes caused by anti-Fas antibody and its potentiation by HIF- $2 \alpha$ expression were also confirmed by DNA fragmentation assays (Supplementary Figure 3a). Counts of apoptotic cells by FACS analysis with fluorescein isothiocyanate (FITC)-conjugated annexin V, or propidium iodide staining showed similar results (Supplementary Figures $3 b$ and $c$ ). Treatment of chondrocytes with anti-Fas antibody did not affect HIF-2 $\alpha$ expression, and knockdown of Epas1 expression using specific small interfering RNA (siRNA) did not affect anti-Fas antibody-induced chondrocyte apoptosis (Supplementary Figure 4).

Similar to the effects of HIF- $2 \alpha$ expression, IL $1 \beta$ treatment enhanced chondrocyte apoptosis in the presence of a low concentration $(0.1 \mu \mathrm{g} / \mathrm{ml})$ of anti-Fas antibody (Figure $3 a$ and Supplementary Figure 5a). The stimulatory effects of IL1 $\beta$ on chondrocyte apoptosis were statistically significant at concentrations as low as $10 \mathrm{pg} / \mathrm{ml}$, a concentration within the range of that found in the synovial fluid of human $O A$ patients $(<20 \mathrm{pg} / \mathrm{ml}) .{ }^{18} \mathrm{IL} 1 \beta$ additionally enhanced chondrocyte apoptosis at high concentrations of anti-Fas antibody (Figure $3 \mathrm{~b}$ ). We have previously shown that IL $1 \beta$ promotes expression of HIF- $2 \alpha$, which, in turn, mediates IL $1 \beta$-induced expression of catabolic factors in chondrocytes. ${ }^{15}$ We therefore examined whether the stimulatory effects of IL $1 \beta$ on chondrocyte apoptosis required HIF- $2 \alpha$ expression. siRNAmediated Epas 1 knockdown significantly blocked the stimulatory effects of IL1 $\beta$ on chondrocyte apoptosis in the presence of anti-Fas antibody (Figure $3 \mathrm{c}$ and Supplementary Figure $5 b$ ). Therefore, HIF-2 $\alpha$ appears to contribute to the induction and enhancement of anti-Fas antibody-dependent chondrocyte apoptosis by IL1 $\beta$.

HIF-2 $\alpha$ regulates chondrocyte apoptosis in OA cartilage. To validate the role of HIF-2 $\alpha$ in chondrocyte apoptosis during $\mathrm{OA}$ cartilage destruction in vivo, we overexpressed HIF-2 $\alpha$ in cartilage tissue by injecting Ad-Epas1 into mouse knee joints. Consistent with our previous results, ${ }^{15}$ Ad-Epas 1 injection caused HIF- $2 \alpha$ overexpression in association with severe cartilage destruction. Under these conditions, chondrocyte apoptosis was significantly increased in OA cartilage (Figure 4a). Cartilage destruction and a significant increase in chondrocyte apoptosis were also observed in aged (45-week-old) chondrocyte-specific Epas1 TG mice (Figure 4b), which exhibit spontaneous OA cartilage destruction. ${ }^{15}$ The function of HIF-2 $\alpha$ in chondrocyte apoptosis in vivo was further characterized using HIF-2 $\alpha$ knockout (KO) mice. As homozygous HIF-2 $\alpha$ KO mice $\left(E\right.$ pas $\left.1^{-1-}\right)$ die in utero, we used heterozygotes $\left(E p a s 1^{+/-}\right)$ for DMM-induced experimental OA. Consistent with our previous results, ${ }^{15}$ DMM caused cartilage destruction in association with an increase in HIF- $2 \alpha$ expression in wildtype (WT) mice, whereas both were significantly attenuated in Epas $1^{+/-}$mice (Figure 4c). DMM surgery also caused a significant increase in chondrocyte apoptosis in WT mice that paralleled the HIF-2 $\alpha$ expression pattern; this too was blocked in Epas1 ${ }^{+/-}$mice (Figure 4d). 

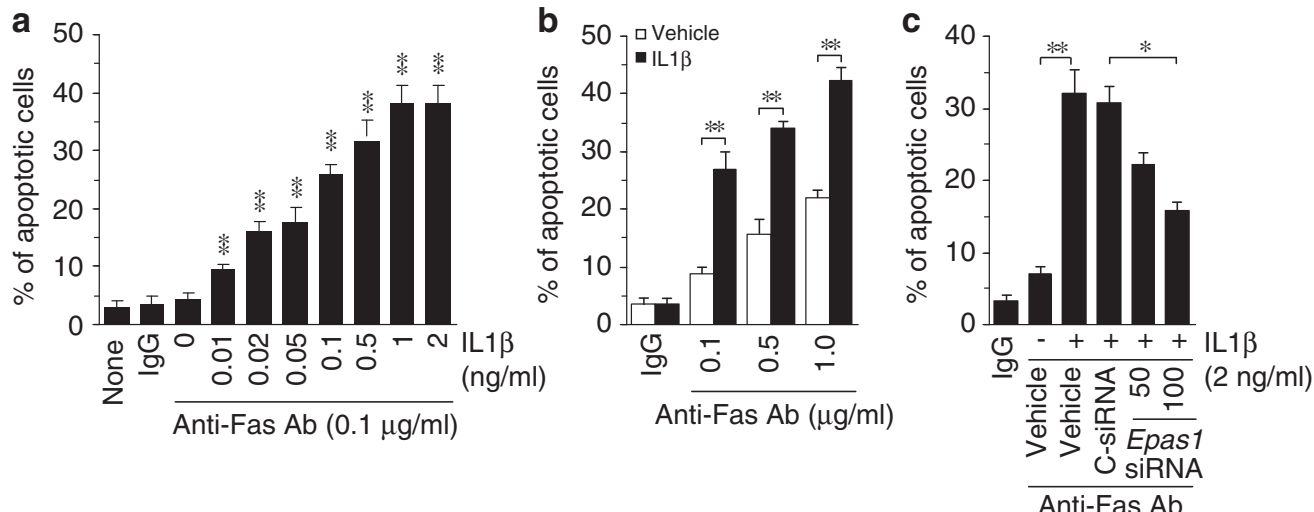

Figure 3 HIF-2 $\alpha$ mediates IL1 $\beta$-induced stimulation of chondrocyte apoptosis. (a) Mouse articular chondrocytes were treated with the indicated amount of IL1 $\beta$ for $24 \mathrm{~h}$. The cells were incubated with $0.1 \mu \mathrm{g} / \mathrm{ml}$ of $\mathrm{lgG}$ or anti-Fas antibody for an additional $6 \mathrm{~h}$, and apoptotic chondrocytes were quantified. (b) Chondrocytes were untreated or treated with $2 \mathrm{ng} / \mathrm{ml}$ of IL1 $\beta$ for $24 \mathrm{~h}$. The cells were then incubated with $1 \mu \mathrm{g} / \mathrm{ml}$ of IgG or anti-Fas antibody for an additional $6 \mathrm{~h}$, and apoptotic chondrocytes were quantified. (c) Chondrocytes were transfected with $100 \mathrm{nM}$ control siRNA (C-siRNA) or the indicated amounts (nM) of Epas1 siRNA. Following incubation for $12 \mathrm{~h}$, the cells were treated with IL $1 \beta$ for $24 \mathrm{~h}$ and exposed to $0.1 \mu \mathrm{g} / \mathrm{ml}$ of IgG or anti-Fas antibody for an additional $6 \mathrm{~h}$; apoptotic chondrocytes were quantified by FACS analysis. Values in a-c are presented as means \pm S.E.Ms $(n=8) .{ }^{*} P<0.001$ and ${ }^{* *} P<0.0005$
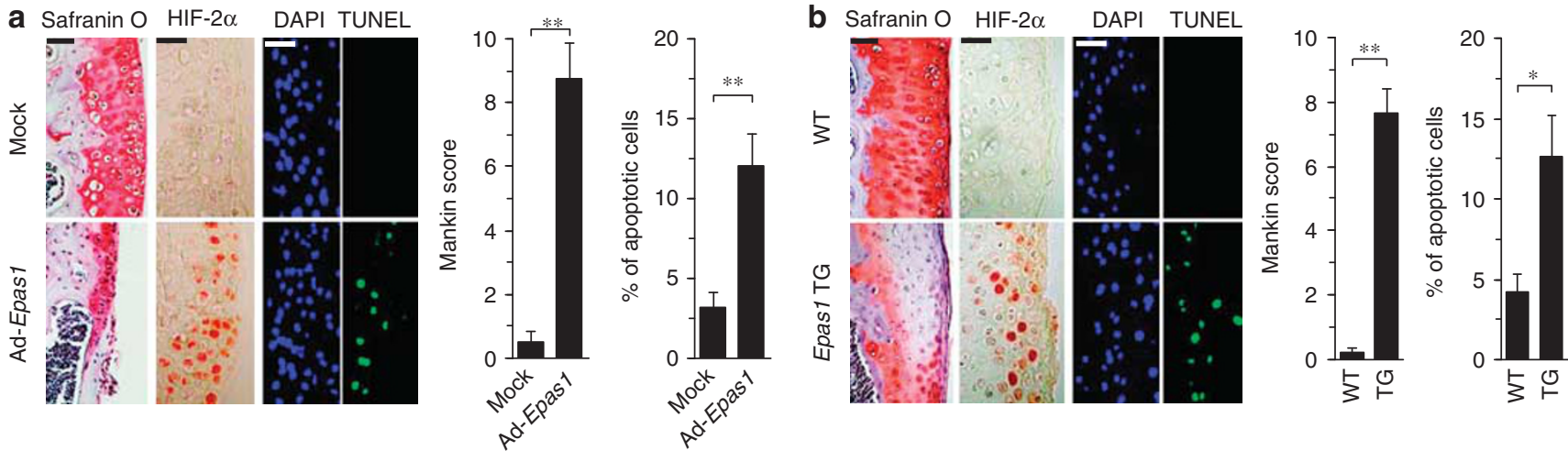

C
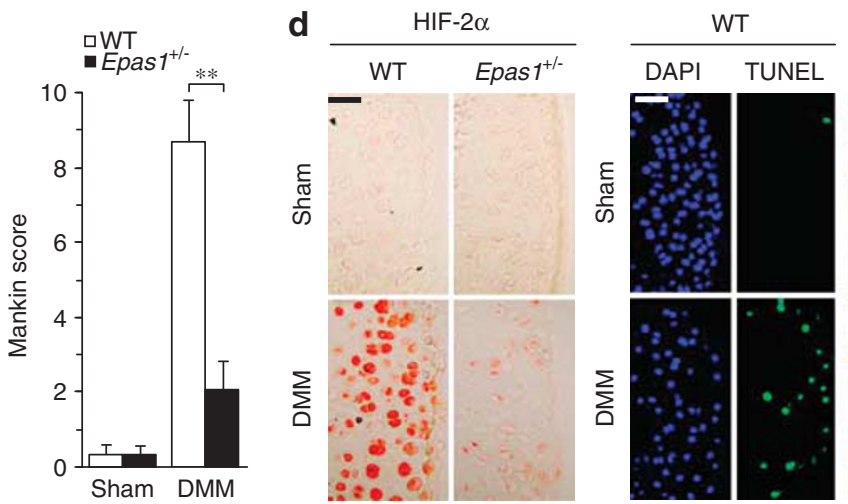

Epas1 $^{+/}$

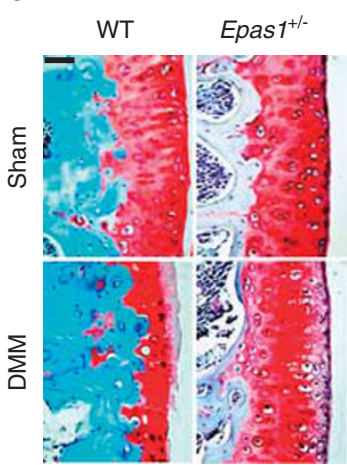

Sham DMM
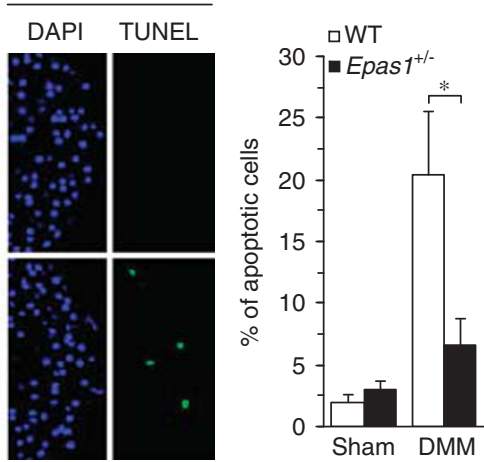

Figure 4 HIF-2 $\alpha$ regulates chondrocyte apoptosis in OA cartilage. (a) Empty Ad (Mock) or Ad-Epas1 virus was injected into knee joints of C57BL/6 mice. After 2 weeks, mice were killed and cartilage sections were used for safranin $O$ staining, HIF-2 $\alpha$ detection, and TUNEL assay. Cartilage destruction was scored by Mankin's method and apoptotic chondrocytes were quantified by TUNEL assay $(n=10)$. (b) Safranin 0 staining, immunohistochemical detection of HIF-2 $\alpha$, and TUNEL assay of cartilage sections from 45-week-old Epas1 TG or WT mice. Cartilage destruction was scored by Mankin's method and apoptotic chondrocytes were quantified by TUNEL assay $(n=6)$. (c) Safranin 0 staining of cartilage sections from sham- and DMM-operated WT and Epas $1^{+/-}$mice. Cartilage destruction was scored using Mankin's method $(n=10)$. (d) HIF-2 $\alpha$ and apoptotic chondrocytes were detected in WT and Epas $1^{+/}$mice. Quantitation of apoptotic cells is shown in the right panel $(n=8)$. Values for Mankin scores and apoptotic cells are presented as means \pm S.E. Ms. of the indicated $n$ 's. ${ }^{\star} P<0.01$ and ${ }^{\star *} P<0.0001$. Scale bar: $50 \mu$ m

The role of HIF-2 $\alpha$ in chondrocyte apoptosis was further examined using chondrocyte-specific Epas1 conditional KO (CKO) mice $\left(\right.$ Epas $1^{\mathrm{fl} / \mathrm{fl}} ;$ Col2a1-Cre). Similar to the results obtained in Epas1 $1^{+/-}$mice, CKO of Epas1 exerted a protective effect against the cartilage destruction induced by DMM surgery, as determined by safranin $O$ staining and 
a

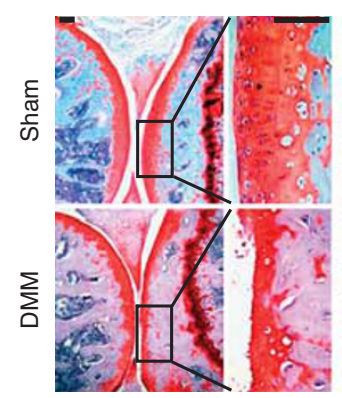

Epast $^{|t| / \mid}$

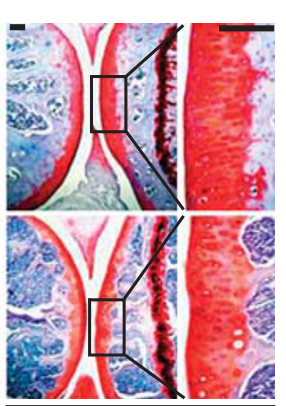

CKO

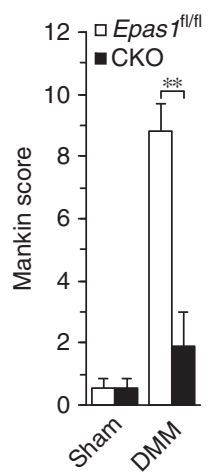

b
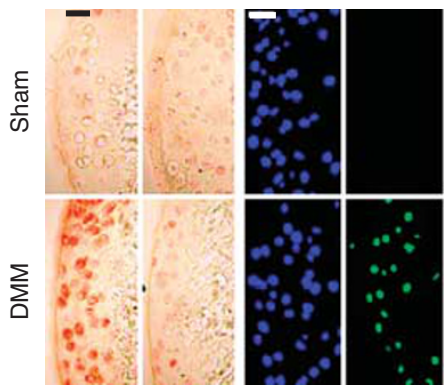

Epas $^{\text {fl/fil }} \quad$ CKO

TUNEL
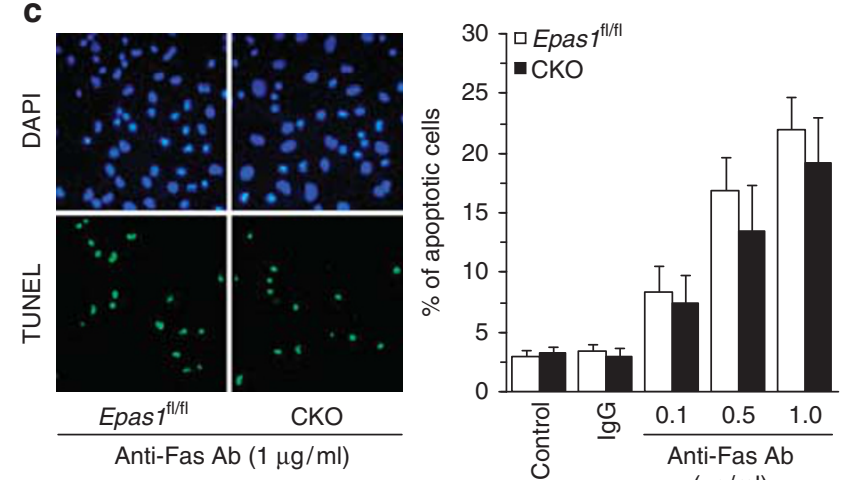

$(\mu \mathrm{g} / \mathrm{ml})$

d

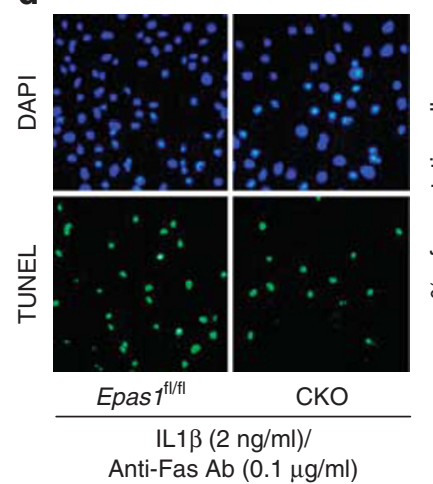

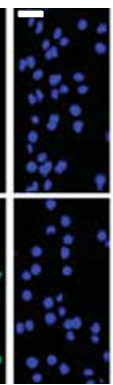

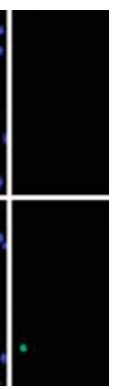

DAPI

CKO
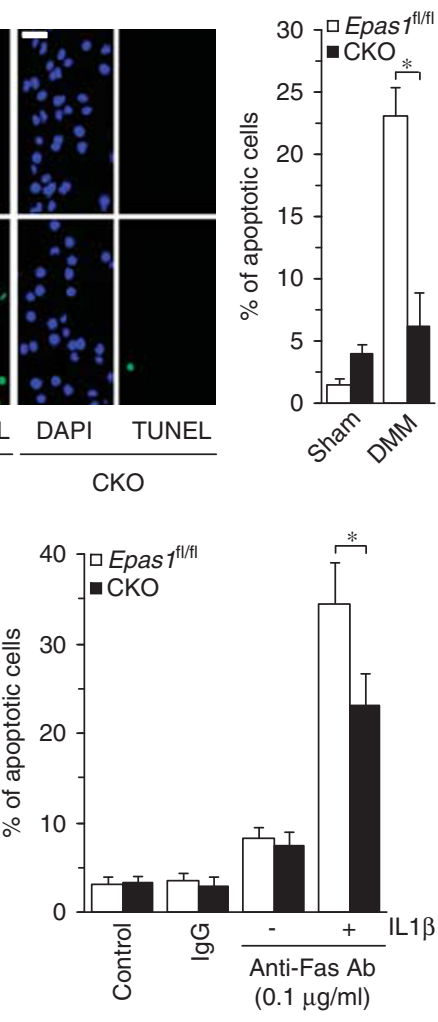

Figure 5 Chondrocyte-specific CKO of Epas1 suppresses chondrocyte apoptosis and OA cartilage destruction. (a and $\mathbf{b})$ Safranin $\mathrm{O}$ staining from control (Epas $1^{\text {t/flfl}}$ ) and CKO mice following DMM surgery or sham operation. Scale bar: $100 \mu \mathrm{m}$. Cartilage destruction was scored by Mankin's method. Values are presented as means \pm S.E.Ms. $(n=12)$ (a). HIF-2 $\alpha$ and apoptotic chondrocytes were detected by immunohistochemical staining and TUNEL assay, respectively. Scale bar: $30 \mu \mathrm{m}$. Apoptotic cells were quantified by FACS analysis. Values are presented as means \pm S.E.Ms. $(n=6)(\mathbf{b})$. (c and d) Primary cultures of articular chondrocytes isolated from Epas1 CKO mice and control Epas $1^{\text {fl/fl }}$ mice were treated with anti-Fas antibody for $6 \mathrm{~h}$. Apoptotic cells were visualized by TUNEL assay and quantified by FACS analysis. Values are presented as means \pm S.E.Ms. $(n=8)(\mathbf{c})$. Articular chondrocytes were treated with $2 \mathrm{ng} / \mathrm{ml}$ of IL $1 \beta$ for $24 \mathrm{~h}$ and $0.1 \mu \mathrm{g} / \mathrm{ml}$ of anti-Fas antibody for an additional $6 \mathrm{~h}$. Apoptotic cells were visualized by TUNEL assay and quantified by FACS analysis. Values are presented as means \pm S.E.Ms. $(n=6)\left(\right.$ d). ${ }^{\star} P<0.005$ and ${ }^{\star \star} P<0.0005$

scoring by Mankin's method (Figure 5a). As expected, DMM surgery did not induce HIF- $2 \alpha$ expression in HIF- $2 \alpha$ CKO mice, and chondrocyte apoptosis was significantly inhibited in these mice (Figure $5 \mathrm{~b}$ ). The role of HIF-2 $\alpha$ in chondrocyte apoptosis was also examined using primary cultures of chondrocytes isolated from WT and HIF- $2 \alpha$ CKO mice. Ectopic expression of HIF- $2 \alpha$ enhanced anti-Fas antibodyinduced apoptosis, whereas deletion of HIF- $2 \alpha$ in chondrocytes did not affect anti-Fas antibody-induced apoptosis (Figure 5c). However, the enhancement of anti-Fas antibody-induced apoptosis by IL1 $\beta$ stimulation was significantly inhibited by HIF- $2 \alpha$ deletion (Figure $5 \mathrm{~d}$ ), confirming that IL $1 \beta$-induced chondrocyte apoptosis is dependent, at least in part, on Epas1 expression.

HIF-2 $\alpha$ stimulates chondrocyte apoptosis by upregulating Fas expression and amplifying downstream signaling. To elucidate the mechanisms of HIF- $2 \alpha$ stimulation of Fas-mediated chondrocyte apoptosis, we investigated the expression levels of Fas and Fasl in articular chondrocytes. Endogenous Fasl expression levels were low and were not changed by IL $1 \beta$ treatment or Ad-Epas 1 infection (data not shown). However, Ad-Epas1 or IL1 $\beta$ markedly enhanced Fas expression, as detected by reverse
transcription-PCR (RT-PCR; Supplementary Figure 6a) and quantified by quantitative RT-PCR (qRT-PCR; Figure 6a). FACS analyses additionally revealed enhanced surface expression of Fas in articular chondrocytes following AdEpas1 infection or IL1 $\beta$ treatment (Figure $6 \mathrm{~b}$ ). The promoter of mouse Fas contains three HIF-2 $\alpha$ binding sites (-CGTG-) at positions $-736,-108$ and -56 , and chromatin immunoprecipitation assays indicated direct binding of HIF- $2 \alpha$ to the proximal two binding sites (Figure 6c). The significance of Fas upregulation in chondrocyte apoptosis was validated by inhibiting Fas expression with specific siRNA. Knockdown of Fas significantly inhibited chondrocyte apoptosis caused by Ad-Epas 1 infection or IL1 $\beta$ treatment (Figure 6d). Finally, we examined Fas expression in chondrocytes of OA cartilage to examine the possible association of Fas upregulation with cartilage destruction. Fas expression was markedly increased in $O A$ cartilage, both in the spontaneous $O A$ cartilage of STR/ort mice and in Ad-Epas1-induced OA cartilage. DMM surgery also increased Fas expression, an effect that was blunted in chondrocyte-specific Epas1 CKO mice (Figure 6e and Supplementary Figures $6 \mathrm{~b}$ and $\mathrm{c}$ ).

As the increase in Fas expression induced by HIF-2 $\alpha$ suggests amplification of apoptotic signals, we next examined Fas downstream signaling. Fas transduces apoptotic signals 


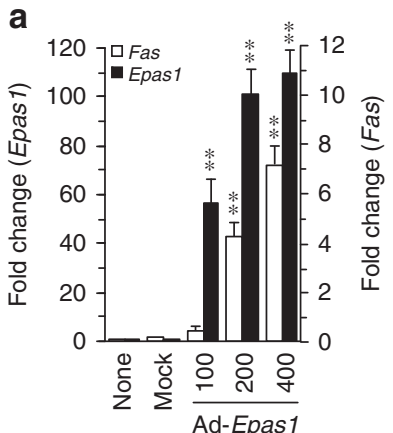

C

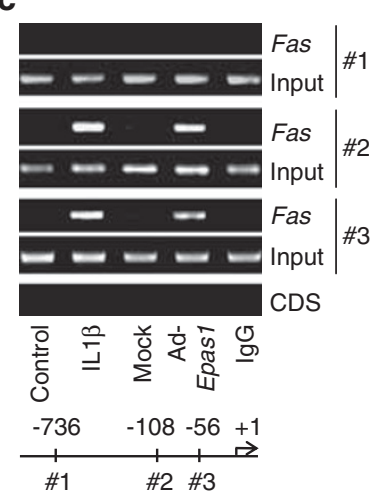

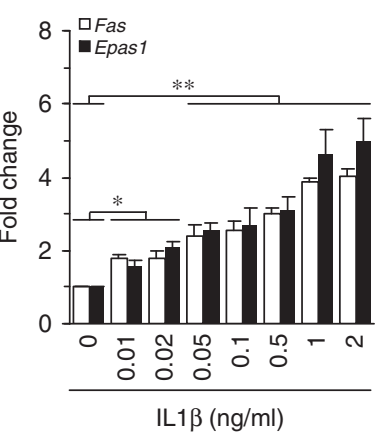

d

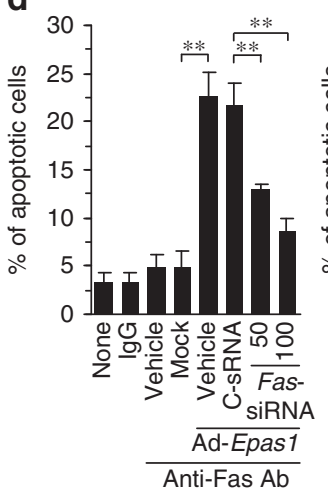

b

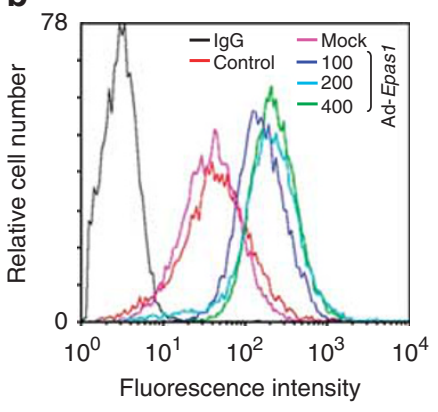

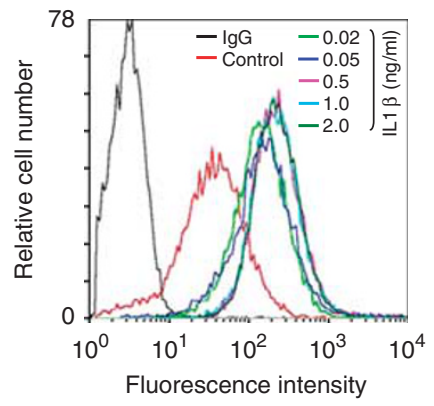

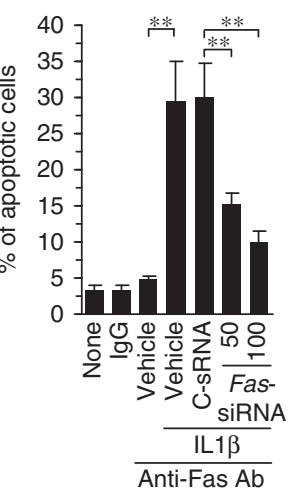

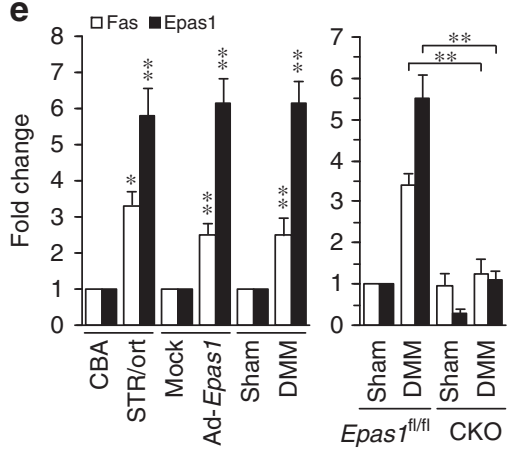

Figure 6 HIF-2 $\alpha$ increases Fas expression in chondrocytes and OA cartilage. (a) Chondrocytes were infected with empty Ad (Mock; 400 multiplicity of infection (MOI)) or Ad-Epas1 (at the indicated MOls) for $24 \mathrm{~h}$ (left) or treated with IL1 $\beta$ for $24 \mathrm{~h}$ (right). Epas1 and Fas transcript levels were quantified by qRT-PCR ( $n=6$ ). (b) Surface expression of Fas in chondrocytes was detected by FACS analysis in cells infected with Ad-Epas1 or treated with IL1 $\beta$. (c) Chromatin immunoprecipitation assays for HIF-2 $\alpha$ binding sites of the Fas promoter. Chondrocytes were left untreated (control), treated with IL1 $\beta$ ( $2 \mathrm{ng} / \mathrm{ml}$ ), or infected with Ad-Epas1 at an MOI of 400 . (d) Chondrocytes were infected with $100 \mathrm{nM}$ control (C)-siRNA or Fas siRNA (at the indicated concentrations (nM)). The cells were infected with Ad-Epas 1 (left) at an MOI of 400 or treated with IL1 $\beta$ $(2 \mathrm{ng} / \mathrm{ml})$ in the presence of anti-Fas antibody $(0.1 \mu \mathrm{g} / \mathrm{ml})$. Apoptotic cells were quantified by FACS $(n=6)$. (e) Expression levels of Fas and Epas 1 were quantified by qRTPCR $(n=8)$ in OA cartilage of STR/ort and control CBA mice, Ad (Mock)- or Ad-Epas1-injected mice, and sham- or DMM-operated WT and Epas1 CKO mice. Values for transcript levels and apoptotic cells are presented as means \pm S.E.Ms. of the indicated $n$ 's. ${ }^{*} P<0.01$ and ${ }^{* \star} P<0.001$

by activating an initiator caspase (e.g. caspase-8), which in turn activates an executioner caspase (e.g. caspase-3), followed by stimulation of a proteolytic cascade. ${ }^{19}$ Anti-Fas antibody slightly, but significantly, activated caspase-8 activity, an effect that was dramatically increased by Ad-Epas 1 infection or IL1 $\beta$ treatment (Figure 7a). Anti-Fas antibody more markedly activated caspase-3 than caspase-8. Caspase-3 activity was also markedly increased by Ad-Epas 1 infection or IL1 $\beta$ treatment in the presence of anti-Fas antibody (Figure 7b). Consistent with this, immunofluorescence microscopy (Supplementary Figure 7) and western blot analyses (Figure 7c) revealed that Ad-Epas1 infection or IL1 $\beta$ treatment increased cleavage of caspase-8, caspase-3, and poly (ADP-ribose) polymerase (PARP). Taken together, our results indicate that HIF- $2 \alpha$ stimulates anti-Fas antibodyinduced apoptosis through upregulation of Fas and amplification of downstream signaling.

Fas deficiency in mice inhibits chondrocyte apoptosis and cartilage destruction. Next, we examined the functional relevance of HIF- $2 \alpha$-mediated Fas upregulation in chondrocyte apoptosis and the functional consequence of chondrocyte apoptosis in OA pathogenesis in vivo. To do this, we used the C57BL/6-Lpr/Lpr mouse, which is a Fas-deficient mouse strain. ${ }^{20}$ The increase in chondrocyte apoptosis induced by Ad-Epas1 infection in control mice (C57BL/6) was significantly reduced in Fas-deficient C57BL/ 6-Lpr/Lpr mice (Figure 8a and Supplementary Figure 8). Chondrocyte apoptosis caused by DMM surgery was also significantly reduced in Fas-deficient mice (Figure $8 \mathrm{~b}$ and Supplementary Figure 8). These results indicate that Fas signaling has an important role in the in vivo chondrocyte apoptosis that takes place during OA cartilage destruction caused by DMM surgery or Ad-Epas 1 infection. Finally, the role of Fas in chondrocyte apoptosis was validated using primary cultures of chondrocytes isolated from control and Fas-deficient mice. As expected, anti-Fas antibody-induced chondrocyte apoptosis and the stimulatory effects of AdEpas 1 or IL1 $\beta$ were completely abolished in Fas-deficient chondrocytes (Figure 8c). Furthermore, cartilage destruction induced by Ad-Epas1 infection or DMM surgery was significantly inhibited in C57BL/6- Lpr/Lpr mice, as determined by Makin scores (Figures $8 a$ and $b$ ), supporting a functional link between chondrocyte apoptosis and OA cartilage destruction.

\section{Discussion}

Here, we demonstrated that HIF-2 $\alpha$ potentiates Fas-mediated chondrocyte apoptosis, which, in turn, is associated with OA cartilage destruction. Although overexpression or knockdown 


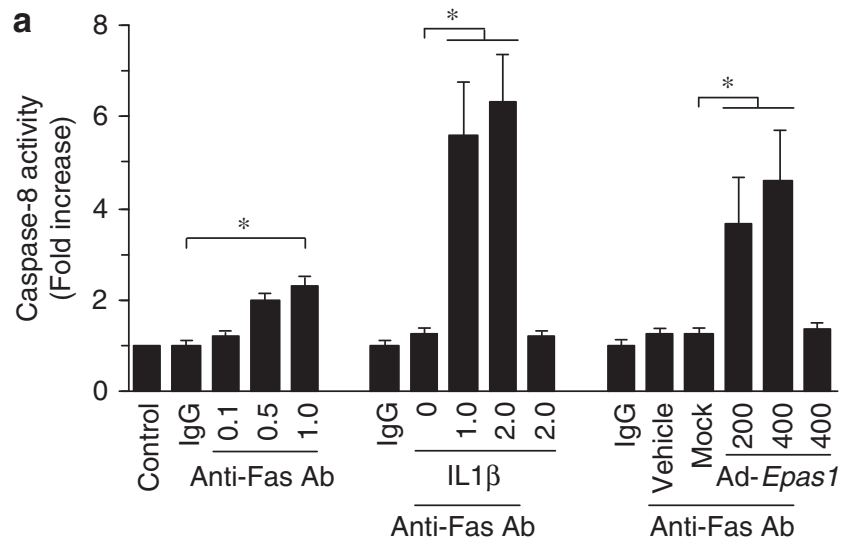

C

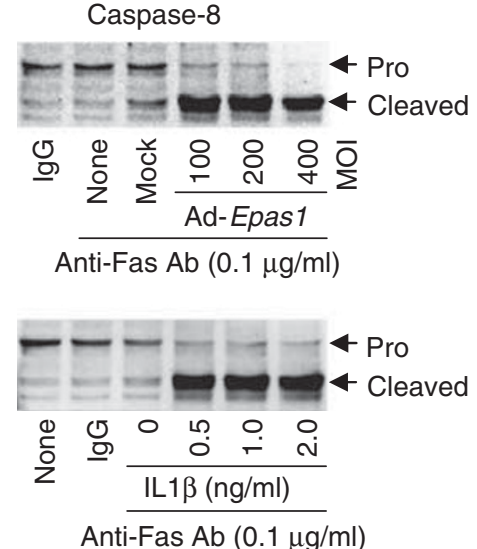

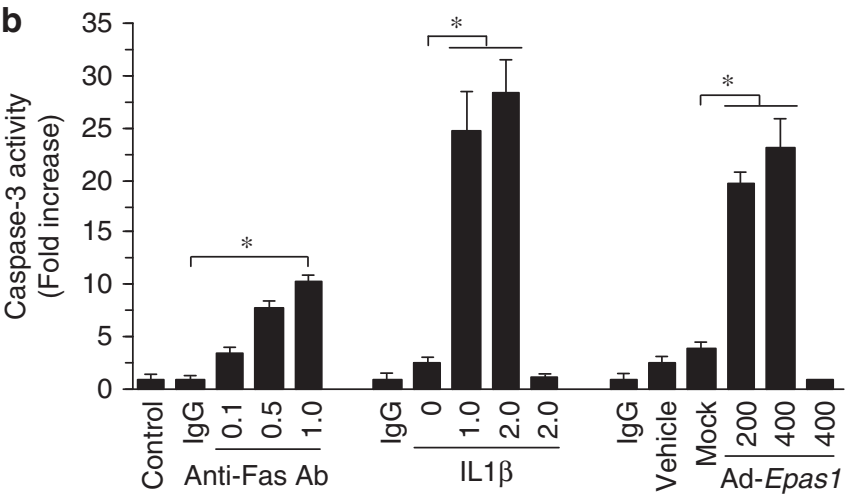

Anti-Fas Ab Anti-Fas Ab
Caspase-3

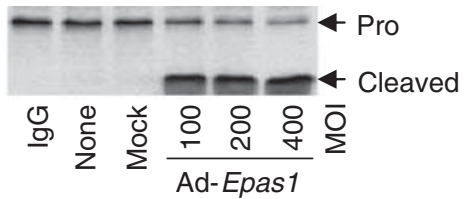

Anti-Fas Ab $(0.1 \mu \mathrm{g} / \mathrm{ml})$

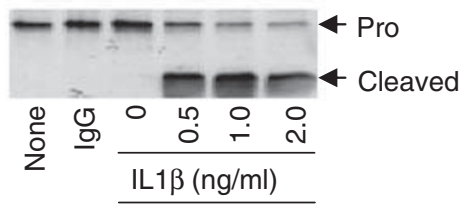

Anti-Fas Ab $(0.1 \mu \mathrm{g} / \mathrm{ml})$

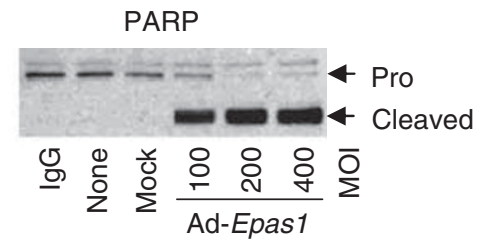

Anti-Fas Ab $(0.1 \mu \mathrm{g} / \mathrm{ml})$

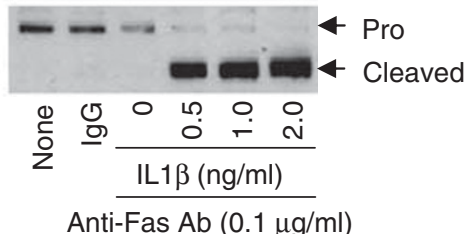

Figure $7 \quad$ HIF-2 $\alpha$ amplifies apoptotic signaling. (a and b) Mouse chondrocytes were treated with $\mathrm{lgG}(1 \mu \mathrm{g} / \mathrm{ml})$ or with the indicated amounts ( $\mu \mathrm{g} / \mathrm{ml})$ of anti-Fas antibody. Alternatively, the cells were treated with IL $1 \beta$ (ng/ml), empty Ad (Mock; 400 multiplicity of infection (MOI)) or with Ad-Epas 1 (at the indicated MOls) for $24 \mathrm{~h}$, and incubated with $0.1 \mu \mathrm{g} / \mathrm{ml}$ anti-Fas antibody for an additional $6 \mathrm{~h}$. Activities of caspase-8 (a) and caspase-3 (b) were measured using the respective assay kits. Values are presented as means \pm S.E.Ms. ( $\left.{ }^{\star} P<0.001 ; n=6\right)$. (c) Mouse articular chondrocytes were untreated or treated with the indicated amounts (ng/ml) of IL $1 \beta$, or infected with empty Ad (Mock; $400 \mathrm{MOI}$ ) or Ad-Epas1 (at the indicated MOls) for $24 \mathrm{~h}$. The cells were exposed to $0.1 \mu \mathrm{g} / \mathrm{ml}$ of anti-Fas antibody for an additional $6 \mathrm{~h}$. Both pro-forms and cleaved-forms of caspase-3, caspase-8, and PARP on the same blot were detected by western blot analysis using antibodies recognizing both forms

of HIF-2 $\alpha$ alone did not modulate chondrocyte apoptosis, HIF-2 $\alpha$ markedly potentiated Fas-mediated apoptosis, an action that reflected upregulation of Fas expression and the consequent amplification of apoptotic signaling (see Figure $8 d$ ). We also demonstrated that HIF-2 $\alpha$ overexpression in mouse cartilage increased chondrocyte apoptosis and cartilage destruction, whereas Epas1 KO mice showed a reduction in both chondrocyte apoptosis and cartilage destruction. Furthermore, mice lacking the Fas gene exhibited reduced chondrocyte apoptosis and OA cartilage destruction. Therefore, our results provide evidence for a link between chondrocyte apoptosis and cartilage destruction by HIF- $2 \alpha$.

The results of in vitro experiments using articular chondrocytes indicate that HIF- $2 \alpha$ causes chondrocyte apoptosis at low concentrations of anti-Fas antibody and markedly enhances apoptosis at high antibody concentrations. The induction and enhancement of chondrocyte apoptosis by HIF- $2 \alpha$ appears to be attributable to its capacity to increase Fas expression. Indeed, the Fas gene is a direct target of HIF- $2 \alpha$ in mouse articular chondrocytes. The significance of Fas upregulation was directly demonstrated by the observation that knockdown of Fas expression inhibited the potentiation of chondrocyte apoptosis by Ad-Epas 1 infection or IL1 $\beta$ treatment. Ligand-stimulated Fas receptors initiate apoptotic signaling by activating an initiator caspase, such as caspase-8, which is activated by self-cleavage. The activated caspase-8, in turn, stimulates an executioner caspase, such as caspase-3, to activate a proteolysis cascade. ${ }^{19}$ Consistent with this, HIF- $2 \alpha$ potentiated the activation of initiator caspase-8 and effector caspase-3, as well as cleavage of the caspase-3 target protein, PARP. We therefore conclude that HIF- $2 \alpha$ potentiates chondrocyte apoptosis through upregulation of Fas and amplification of downstream apoptotic signaling.

We have previously shown that HIF- $2 \alpha$ expression is stimulated by IL1 $\beta$ in articular chondrocytes. ${ }^{15}$ In the current study, we observed that anti-Fas antibody-induced chondrocyte apoptosis was significantly enhanced by IL $1 \beta$ treatment. The stimulatory effects of IL1 $\beta$ on chondrocyte apoptosis appear to be mediated by HIF- $2 \alpha$ expression because knockdown of Epas1 inhibited IL1 $\beta$-induced enhancement of apoptosis. However, although IL1 $\beta$-enhanced apoptosis was markedly inhibited in HIF- $2 \alpha$ KO chondrocytes, IL1 $\beta$ still enhanced anti-Fas antibody-induced chondrocyte apoptosis. This indicates the existence of HIF- $2 \alpha$-independent apoptosis-inducing mechanisms, although these were not 

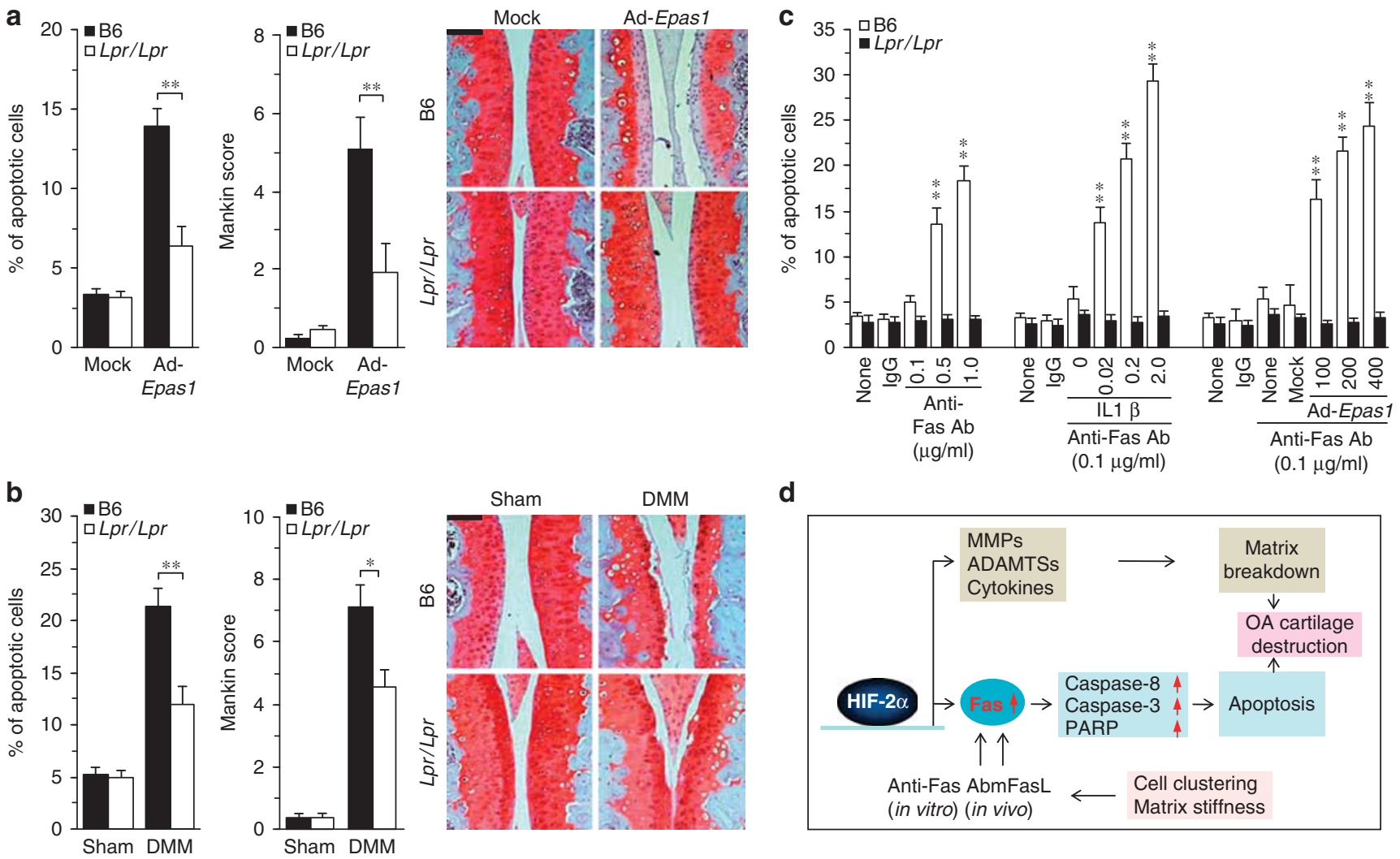

d

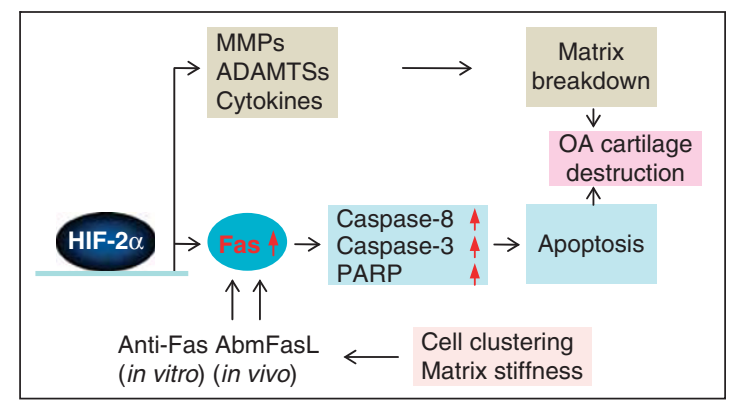

Figure 8 Fas-deficient mice exhibit markedly inhibited chondrocyte apoptosis and cartilage destruction. (a) Apoptotic chondrocytes were quantified by TUNEL assay in Fas-deficient C57BL/6-Lpr/Lpr mice ( $L p r / L p r)$ and C57BL/6 control mice (B6), after DMM and sham operations $(n=9)$. Cartilage destruction was visualized by safranin 0 staining and quantified by Mankin's method ( $n=9$ ). (b) Control (B6) and Lpr/Lpr mice were injected with empty Ad (Mock) or Ad-Epas1, and apoptotic chondrocytes were quantified ( $n=7)$. Cartilage was stained with safranin 0 , and destruction was scored by Makin's method $(n=7)$. (c) Chondrocytes isolated from control (B6) and $L p r / L p r$ mice were untreated, treated with IL1 $\beta(\mathrm{nM})$, or infected with empty Ad (Mock) or Ad-Epas1 at an MOI (multiplicity of infection) of 400 . The cells were treated with normal IgG or the indicated concentrations of anti-Fas antibody, and apoptotic cells were quantified by FACS analysis $(n=8)$. (d) Schematic diagram depicting HIF-2 $\alpha$ regulation of chondrocytes apoptosis. Values in $\mathbf{a}, \mathbf{b}$, and $\mathbf{c}$ are presented as means \pm S.E.Ms. of the indicated $n$ 's. ${ }^{*} P<0.01$ and ${ }^{* \star} P<0.001$. Scale bar: $100 \mu \mathrm{m}$

explored in this study. The effect of IL $1 \beta$ on chondrocyte apoptosis is a matter of controversy and appears to depend on experimental conditions. Similar to our results, it has been shown that IL1 $\beta$ induces apoptosis of rat $^{21}$ and human ${ }^{22}$ OA chondrocytes. In contrast, Kühn et al. ${ }^{23}$ have reported that IL $1 \beta$ protects against anti-Fas antibody-induced apoptosis of human chondrocytes. Although additional studies will be required to resolve these discrepancies, they could reflect differences in experimental conditions. We used passage 0 primary cultured mouse articular chondrocytes, whereas Kühn et al. used second-passage human OA chondrocytes. Serial passage in culture is known to cause a loss of the differentiated chondrocyte phenotype, ${ }^{24}$ and such a change in differentiation status could modulate IL1 $\beta$ effects. Another possible explanation for the discrepant findings is a difference in IL1 $\beta$ treatment conditions. Kühn et al. ${ }^{23}$ co-treated chondrocyte with anti-Fas antibody and IL $\beta$ for $14 \mathrm{~h}$, whereas we pretreated chondrocytes with IL1 $\beta$ or Ad-Epas 1 for $24 \mathrm{~h}$ before treatment with anti-Fas antibody. Pretreatment with IL $1 \beta$ or HIF- $2 \alpha$ overexpression could alter the gene expression profile in chondrocytes, leading to a more apoptosispromoting state. Indeed, we observed that IL1 $\beta$ and HIF- $2 \alpha$ enhanced Fas expression in chondrocytes. Nevertheless, our current results clearly indicate that pretreatment with IL1 $\beta$, and HIF-2 $\alpha$ overexpression markedly enhanced chondrocyte apoptosis, suggesting a contribution of HIF-2 $\alpha$ to OA cartilage destruction.

The significance of HIF-2 $\alpha$ in chondrocyte apoptosis in vivo was suggested by the observations that HIF- $2 \alpha$ and Fas levels were markedly increased in human OA cartilage and various mouse models of OA cartilage. Consistent with this, a number of studies have indicated that Fas expression is upregulated in OA chondrocytes. Fas levels are reported to be higher in aged cartilage, and are correlated with the decrease in cellularity in rabbit articular cartilage during aging. ${ }^{12,13}$ Upregulation of Fas is also observed in rabbit chondrocytes after OA induction. ${ }^{10}$ In human articular cartilage, expression of Fas is increased in OA chondrocytes, ${ }^{11}$ and Fas expression is higher in close proximity to OA lesions than in regions distal to the lesion. ${ }^{7}$ In the current study, we found that FasL was expressed in chondrocytes, although the expression levels were low. Other studies have also reported expression of FasL in chondrocytes. For instance, mRNA levels of FasL are higher in aged cartilage, and FasL expression is increased in rabbit $O A$ cartilage. ${ }^{10,12}$ FasL upregulation is also observed in human OA cartilage and chondrocytes. ${ }^{11}$ In these previous studies, 
however, it was not determined whether the increase in FasL mRNA levels resulted in an increase in the expression of membrane-bound FasL, which is linked to the apoptotic pathway. Our current results indicate that HIF-2 $\alpha$ upregulates Fas expression without modulating FasL expression in chondrocytes. Therefore, we speculate that increased Fas expression potentiates death signaling in chondrocytes, even in the context of the low FasL levels in chondrocytes. However, this interpretation should be considered with care. Although upregulation of Fas on chondrocytes makes the cells a potential target for Fas/FasL-induced apoptosis, it remains to be clarified whether Fas upregulation is sufficient to cause chondrocyte apoptosis in the presence of low FasL levels. Indeed, aggregation of pre-assembled Fas trimers by FasL trimers or antagonistic Abs has been shown to trigger apoptosis in vivo and in vitro, respectively. ${ }^{3,4}$ Additionally, the dense nature of cartilage matrix and the existence of chondrocyte as single cells in cartilage tissue may hinder the free movement of FasL on the cell membrane, thus interfering with receptor engagement on chondrocytes. However, changes in cartilage stiffness during OA progression, ${ }^{25}$ and aggregation of chondrocytes in OA cartilage may make FasL movement and receptor engagement possible.

Consistent with the upregulation of HIF-2 $\alpha$ and Fas in OA cartilage, Epas $1^{+/-}$mice and Epas1 CKO mice showed a reduction in both chondrocyte apoptosis and cartilage destruction. The functional relevance of HIF- $2 \alpha$-mediated Fas upregulation in chondrocyte apoptosis and the functional consequence of chondrocyte apoptosis in OA pathogenesis were explored in vivo using C57BL/6-Lpr/Lpr mice, which lack the Fas gene. ${ }^{20}$ Mice of the MRL strain with the lymphoproliferation $(L p r)$ mutation spontaneously develop a complex, rheumatoid arthritis-like immunological disease that is caused by a mutation in the Fas gene. ${ }^{20}$ However, other strains of mice with the Lpr mutation, such as C57BL/6, do not develop spontaneous arthritis. ${ }^{26}$ Therefore, we used $L p r / L p r$ mice inbred on a C57BL/6 background (C57BL/6-Lpr/Lpr) as a Fas-deficient mouse model. Our results indicate that a deficiency of Fas inhibited in vivo chondrocyte apoptosis upon DMM surgery or Ad-Epas1 infection. This supports our hypothesis that induction and enhancement of chondrocyte apoptosis is due to Fas upregulation rather than indirect induction of apoptosis by other deleterious effects of HIF- $2 \alpha$ on chondrocytes, such as expression of catabolic factors. Fas-deficient mice also exhibited reduced $O A$ cartilage destruction upon Ad-Epas1 injection or DMM surgery. This supports the functional significance of chondrocyte apoptosis in OA pathogenesis. We have previously shown that HIF- $2 \alpha$ regulates the expression of catabolic factors, such as matrix metalloproteinase (MMP) 3 and MMP $13,{ }^{15}$ which have crucial roles in OA pathogenesis. ${ }^{27,28}$ Therefore, our current results suggest an essential role for HIF- $2 \alpha$-mediated chondrocyte apoptosis in OA pathogenesis in addition to its role in inducing the expression of catabolic factors, such as matrix-degrading enzymes and inflammation mediators.

\section{Materials and Methods}

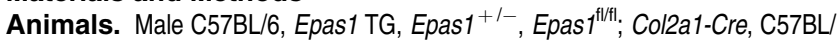
6-Lpr/Lpr, STR/ort, and CBA/CaCrl mice were used for experimental OA studies. Chondrocyte-specific Epas1 TG mice were generated using the Col2a1 promoter and enhancer. ${ }^{15}$ Epas $1^{+/-}$mice, ${ }^{29}$ Epast $1^{\text {fl/fl }}$ mice ${ }^{30}$ and Col2a1-Cre TG mice ${ }^{31}$ were obtained from Jackson Laboratories (Bar Harbor, ME, USA). Epas $1^{1 / 1 / 1}$ mice were crossed with Col2a1-Cre TG mice to generate Epas ${ }^{1 /+}+$; Col2a1-Cre mice. These mice were backcrossed with Epas $1^{\text {fl/fl }}$ mice to generate chondrocyte-specific CKO mice (Epasf ${ }^{\mathrm{fl} / \mathrm{fl}}$; Col2a1-Cre). Primers used for genotyping are described in Supplementary Table 1. C57BL/6-Lpr/Lpr mice ${ }^{20}$ were purchased from Japan SLC, Inc. (Shizuoka, Japan); C57BL/6 mice were used as a congenic control for $L p r / L p r$ mice. Animals were maintained under pathogen-free conditions. All experiments were approved by the Gwangju Institute of Science and Technology Animal Care and Use Committee.

Human OA cartilage and experimental OA in mice. Normal human knee joint cartilage was obtained from patients who experienced meniscus problems during arthroscopic meniscectomy or meniscal repair. Human OA knee joint cartilage was sourced from individuals who had undergone arthroplasty. ${ }^{15}$ The Review Board of the Wonkwang University Hospital approved the use of these materials, and all individuals provided informed, written consent before the operative procedure. Spontaneous OA in STR/ort ${ }^{16}$ and Epas 1 TG mice was examined at 28 and 45 weeks of age, respectively. Experimental OA in mice was induced by DMM surgery; sham-operated mice were used as controls. ${ }^{15,17}$ Experimental $O A$ was also induced by intra-articular injection of Ad-Epas $1\left(1 \times 10^{9}\right.$ plaque forming units (PFU)) in 10-12-week-old male mice; control mice were injected with empty Ad virus (mock infection). ${ }^{15}$ Mice were killed 8 weeks after DMM surgery or 2 weeks after Ad-Epas 1 injection for analysis of cartilage tissue.

Histological analysis and apoptosis assay. Normal and OA human cartilage were frozen, sectioned at 6- $\mu \mathrm{m}$ thickness, and fixed in paraformaldehyde. OA cartilage damage was established based on alcian blue staining, and scored according to the International Cartilage Repair Society grading system. ${ }^{15,32}$ HIF- $2 \alpha$ protein was detected using standard immunohistochemical staining techniques. ${ }^{15}$ Mouse cartilage tissues were fixed in paraformaldehyde, decalcified, embedded in paraffin, and sectioned at 6- $\mu \mathrm{m}$ thickness. Cartilage destruction was evaluated by safranin $\mathrm{O}$ staining and was scored according to Mankin's method. ${ }^{15,33}$ For HIF-2 $\alpha$ immunohistochemical staining, mouse cartilage tissue was scraped off with a blade and embedded in paraffin after fixation with paraformaldehyde, omitting the decalcification step. HIF-2 $\alpha$ was detected in sections (5- $\mu \mathrm{m}$ thick) using standard immunohistochemical staining techniques. ${ }^{15}$ Apoptosis of articular chondrocytes in cartilage tissues was determined by TUNEL assay using a kit from Roche Diagnostics (Mannheim, Germany). Specimens were visualized under a fluorescence microscope. The number of apoptotic chondrocytes in relation to the total number of cells was quantified in tissue sections. More than three fields of microscopic view in each section, and multiple sections (more than three) from at least six different experimental animals in each experimental group were used.

Primary culture of articular chondrocytes and apoptosis assay. Mouse articular chondrocytes were obtained from 6-day-old ICR mice, Epast ${ }^{1 / / 1}$ mice, Epast ${ }^{\text {f/flil }}$ Col2a1-Cre mice, and C57BL/6-Lpr/Lpr mice. Chondrocytes were isolated from femoral heads, femoral condyles and tibial plateaus of each mouse as described previously, ${ }^{34}$ and maintained as a monolayer in Dulbecco's Modified Eagle Medium containing 10\% fetal bovine serum. Apoptosis was induced in culture day-3 chondrocytes by treating with anti-mouse Fas antibody. Briefly, chondrocytes were treated for $6 \mathrm{~h}$ with the indicated amounts of anti-mouse Fas antibody (BD Biosciences, Franklin Lakes, NJ, USA) in the presence of $0.5 \mu \mathrm{g} / \mathrm{ml}$ of recombinant protein $\mathrm{G}$ to enhance receptor cross-linking. Hamster $\lg _{2}(1 \mu \mathrm{g} / \mathrm{ml})$ in the presence of protein $\mathrm{G}$ was used as a control. The effects of HIF-2 $\alpha$ and IL1 $\beta$ were examined by treating chondrocytes with the indicated amount of empty Ad (mock), Ad-Epas1, or IL1 $\beta$ ( $2 \mathrm{ng} / \mathrm{ml}$ ) for $24 \mathrm{~h}$. The cells were exposed to anti-Fas antibody and protein $G$ for an additional $6 \mathrm{~h}$. Apoptotic death of chondrocytes was confirmed by TUNEL assay. ${ }^{35}$ All experiments with each primary culture were performed in duplicate in Dulbecco's Modified Eagle Medium containing $0.5 \%$ fetal bovine serum. $n$ 's indicate the number of primary cultures. Chondrocyte apoptosis was also determined by DNA fragmentation assay and flow cytometry based on the number of cells containing fragmented DNA. Apoptotic chondrocytes were quantified by FACS analysis using cells stained with FITC-conjugated annexin $\mathrm{V}$ or propidium iodide (BD Biosciences). ${ }^{35}$

Assay of Fas expression. mRNA levels of Fas in articular chondrocytes were detected by RT-PCR and quantified by GRT-PCR. PCR primers and experimental conditions are summarized in Supplementary Table 1. Cell surface 
Fas expression was assessed by immunofluorescence microscopy and FACS analysis. For FACS analysis, mouse articular chondrocytes were untreated or treated with IL $1 \beta$ or infected with Ad-Epas1 for $24 \mathrm{~h}$. The cells were harvested, suspended to a concentration of $1 \times 10^{6} \mathrm{cells} / \mathrm{ml}$ in ice-cold PBS, and incubated for 20 min at $4{ }^{\circ} \mathrm{C}$ with $5 \mu \mathrm{g} / \mu$ of R-phycoerythrin (PE)-conjugated hamster anti-mouse Fas antibody (clone Jo2; BD Biosciences). PE-conjugated hamster IgG2 (BD Biosciences) was used as a control IgG. After washing twice with PBS, cells were analyzed using a FACScan flow cytometry system (EPIC XL; Beckman Coulter, Brea, CA, USA). For immunofluorescence microscopy of Fas, chondrocytes were isolated from C57BL/6 mice, cultured on coverslips for 4 days, and incubated for $1 \mathrm{~h}$ at room temperature with $2 \mu \mathrm{g} / \mu \mathrm{l}$ of FITC-conjugated hamster anti-mouse Fas antibody. FITC-conjugated hamster IgG2 was used as a control (BD Biosciences). We also used chondrocyte isolated from Fas-deficient $L p r / L p r$ mice as a negative control for Fas expression. Fas expression was additionally examined by using PE-conjugated hamster anti-mouse Fas antibody (clone Jo2) or PE-conjugated hamster IgG2 (BD Biosciences) as a control antibody. Fas surface expression was visualized under an Olympus FV1000 confocal laser-scanning biological microscope (Olympus, Tokyo, Japan).

Caspase assay. Activities of caspase- 3 and caspase- 8 were determined using a caspase colorimetric assay kit (R\&D Systems Inc., Minneapolis, MN, USA). Briefly, chondrocyte lysates were incubated with substrate for caspase-3 (DEVDpNA) or caspase-8 (IETD-pNA) for $2 \mathrm{~h}$ at $37^{\circ} \mathrm{C}$. The activity of each caspase was determined by measuring absorbance at $405 \mathrm{~nm}$. Cleavage of caspases and PARP was determined by immunofluorescence microscopy using antibodies specific to cleaved-forms. Both pro-forms and cleaved-forms of caspases and PARP on the same blot were detected by western blot analysis using antibodies recognizing both forms. Antibodies against caspase-3 (rabbit anti-human caspase-3 polyclonal; \#9662) and PARP (rabbit anti-PARP polyclonal; \#9542) were obtained from Cell Signaling Technology (Danvers, MA, USA). Rabbit anti-caspase-8 polyclonal antibody (\#AB1879) was purchased from Millipore (Temecula, CA, USA).

siRNA, RT-PCR, and qRT-PCR. Total RNA was extracted from human and mouse cartilage tissue, and articular chondrocytes. For mouse cartilage tissue, knee joints from control and OA cartilage were scraped with a blade to remove cartilage, and RNA was isolated from the removed cartilage using the TRI reagent (Molecular Research Center Inc., Cincinnati, OH, USA). The RNA was reverse transcribed, and the resulting CDNA was amplified by PCR. PCR primers and experimental conditions are summarized in Supplementary Table 1. Transcript levels were quantified by qRT-PCR. The siRNA sequences that silenced Epas 1 most effectively were used in this study. ${ }^{15}$ The Fas siRNA pool was purchased from Dharmacon (Chicago, IL, USA). Non-silencing siRNA was used as a negative control. Chondrocytes cultured for $60 \mathrm{~h}$ were transfected for $6 \mathrm{~h}$ with siRNA using Lipofectamine 2000 (Invitrogen, Carlsbad, CA, USA), and infected with Ad-Epas1 or treated with IL1 $\beta$.

Chromatin immunoprecipitation assays. Chromatin immunoprecipitation assays of mouse articular chondrocytes treated with IL $1 \beta$ or infected with Ad-Epas1 were performed using a kit (Millipore), as described by the manufacturer. Briefly, cells were fixed with $1 \%$ formaldehyde for $10 \mathrm{~min}$ to cross-link protein and bound DNA, and suspended in sodium dodecyl sulfate lysis buffer. After preclearing lysates with antirabbit lgG, chromatin was incubated with $2 \mu \mathrm{g}$ anti-HIF-2 $\alpha$ antibody (Novus Biologicals, Littleton, CO, USA). Antibody-protein-DNA complexes were isolated by precipitation with protein A-agarose. Pellets were eluted with elution buffer ( $1 \%$ sodium dodecyl sulfate and $0.1 \mathrm{M} \mathrm{NaHCO}_{3}$ ), mixed with $5 \mathrm{M} \mathrm{NaCl}$, and heated for $4 \mathrm{~h}$ at $65^{\circ} \mathrm{C}$. DNA was purified using phenol extraction and amplified by PCR. The primers were designed to allow amplification of the three different HIF-response element-containing regions of the Fas promoter (Supplementary Table 1).

Statistical analysis. Statistical significance was evaluated using Student's $t$-test. Significance was accepted at the 0.05 level of probability $(P<0.05)$.

\section{Conflict of Interest}

The authors declare no conflict of interest.

Acknowledgements. This work was supported by Grants from the National Research Foundation of Korea (2010-0001619, 2010-0026293, and 2010-0015783) and the Korea Healthcare Technology R\&D Project (A101793).
1. Goldring MB, Goldring SR. Osteoarthritis. J Cell Physiol 2007; 213: 626-634.

2. Hashimoto M, Nakasa T, Hikata T, Asahara H. Molecular network of cartilage homeostasis and osteoarthritis. Med Res Rev 2008; 28: 464-481.

3. Kühn K, D'Lima DD, Hashimoto S, Lotz M. Cell death in cartilage. Osteoarthritis Cartilage 2004; $12: 1-16$.

4. Kim HA, Blanco FJ. Cell death and apoptosis in osteoarthritic cartilage. Curr Drug Targets 2007; 8: 333-345.

5. Blanco FJ, Guitian R, Vazquez-Martul E, de Toro FJ, Galdo F. Osteoarthritis chondrocytes die by apoptosis. A possible pathway for osteoarthritis pathology. Arthritis Rheum 1998; 41: 284-289

6. Heraud F, Heraud A, Harmand MF. Apoptosis in normal and osteoarthritic human articular cartilage. Ann Rheum Dis 2000; 59: 959-965.

7. Kim HA, Lee YJ, Seong SC, Choe KW, Song YW. Apoptotic chondrocyte death in human osteoarthritis. J Rheumatol 2000; 27: 455-462.

8. Hashimoto S, Ochs RL, Komiya S, Lotz M. Linkage of chondrocyte apoptosis and cartilage degradation in human osteoarthritis. Arthritis Rheum 1998; 41: 1632-1638.

9. Masuko-Hongo K, Sakata M, Yuan GH, Onuma H, Nakamura H, Aoki H et al. Expression of Fas-associated death domain-like interleukin-1beta-converting enzyme (FLICE) inhibitory protein (FLIP) in human articular chondrocytes: possible contribution to the resistance to Fas-mediated death of in vitro cultured human articular chondrocytes. Rheumatol Int 2001; 21: 112-121.

10. Pennock AT, Robertson CM, Emmerson BC, Harwood FL, Amiel D. Role of apoptotic and matrix-degrading genes in articular cartilage and meniscus of mature and aged rabbits during development of osteoarthritis. Arthritis Rheum 2007; 56: 1529-1536.

11. Wei L, Sun XJ, Wang Z, Chen Q. CD95-induced osteoarthritic chondrocyte apoptosis and necrosis: dependency on p38 mitogen-activated protein kinase. Arthritis Res Ther 2006; 8 : R37-R47.

12. Todd Allen R, Robertson CM, Harwood FL, Sasho T, Williams SK, Pomerleau AC et al. Characterization of mature vs aged rabbit articular cartilage: analysis of cell density, apoptosis-related gene expression and mechanisms controlling chondrocyte apoptosis. Osteoarthritis Cartilage 2004; 12: 917-923.

13. Robertson CM, Pennock AT, Harwood FL, Pomerleau AC, Allen RT, Amiel D. Characterization of pro-apoptotic and matrix-degradative gene expression following induction of osteoarthritis in mature and aged rabbits. Osteoarthritis Cartilage 2006; 14: $471-476$

14. Hashimoto H, Tanaka M, Suda T, Tomita T, Hayashida K, Takeuchi E et al. Soluble Fas ligand in the joints of patients with rheumatoid arthritis and osteoarthritis. Arthritis Rheum 1998; 41: 657-662.

15. Yang $\mathrm{S}$, Kim J, Ryu JH, Oh $\mathrm{H}$, Chun $\mathrm{CH}$, Kim BJ et al. Hypoxia-inducible factor2alpha is a catabolic regulator of osteoarthritic cartilage destruction. Nat Med 2010; 16 : 687-693.

16. Mason RM, Chambers MG, Flannelly J, Gaffen JD, Dudhia J, Bayliss MT et al The STR/ort mouse and its use as a model of osteoarthritis. Osteoarthritis Cartilage 2001; 9: 85-91.

17. Glasson SS, Blanchet TJ, Morris EA. The surgical destabilization of the medial meniscus (DMM) model of osteoarthritis in the 129/SvEv mouse. Osteoarthritis Cartilage 2007; 15: 1061-1069.

18. Barakat $\mathrm{AF}$, Elson $\mathrm{CJ}$, Westacott $\mathrm{Cl}$. Susceptibility to physiological concentrations of IL-1beta varies in cartilage at different anatomical locations on human osteoarthritic knee joints. Osteoarthritis Cartilage 2002; 10: 264-269.

19. Bratton SB, MacFarlane M, Cain K, Cohen GM. Protein complexes activate distinct caspase cascades in death receptor and stress-induced apoptosis. Exp Cell Res 2000; 256: $27-33$.

20. Watanabe-Fukunaga $\mathrm{R}$, Brannan $\mathrm{Cl}$, Copeland NG, Jenkins NA, Nagata $\mathrm{S}$. Lymphoproliferation disorder in mice explained by defects in Fas antigen that mediates apoptosis. Nature 1992; 356: 314-317.

21. Zhou PH, Liu SQ, Peng H. The effect of hyaluronic acid on IL-1beta-induced chondrocyte apoptosis in a rat model of osteoarthritis. J Orthop Res 2008; 26 : 1643-1648.

22. Kim J, Xu M, Xo R, Mates A, Wilson GL, Pearsall IV AW et al. Mitochondrial DNA damage is involved in apoptosis caused by pro-inflammatory cytokines in human OA chondrocytes. Osteoarthritis Cartilage 2010; 18: 424-432.

23. Kühn K, Hashimoto S, Lotz M. IL-1 beta protects human chondrocytes from CD95-induced apoptosis. J Immunol 2000; 164: 2233-2239.

24. Yoon YM, Kim SJ, Oh CD, Ju JW, Song WK, Yoo YJ et al. Maintenance of differentiated phenotype of articular chondrocytes by protein kinase $\mathrm{C}$ and extracellular signal-regulated protein kinase. J Biol Chem 2002; 277: 8412-8420.

25. Stolz M, Gottardi R, Raiteri R, Miot S, Martin I, Imer R et al. Early detection of aging cartilage and osteoarthritis in mice and patient samples using atomic force microscopy. Nat Nanotechnol 2009; 4: 186-192.

26. Ratkay LG, Tait B, Tonzetich J, Waterfield JD. Lpr and MRL background gene involvement in the control of adjuvant enhanced arthritis in MRL-Ipr mice. J Autoimmun 1994; 7 : $561-573$

27. Blom $\mathrm{AB}$, van Lent PL, Libregts $\mathrm{S}$, Holthuysen $\mathrm{AE}$, van der Kraan PM, van Rooijen $\mathrm{N}$ et al. Crucial role of macrophages in matrix metalloproteinase-mediated cartilage destruction during experimental osteoarthritis: involvement of matrix metalloproteinase 3. Arthritis Rheum 2007; 56: 147-157. 
28. Little CB, Barai A, Burkhardt D, Smith SM, Fosang AJ, Werb Z et al. Matrix metalloproteinase 13-deficient mice are resistant to osteoarthritic cartilage erosion but not chondrocyte hypertrophy or osteophyte development. Arthritis Rheum 2009; 60: 3723-3733.

29. Tian H, Hammer RE, Matsumoto AM, Russell DW, McKnight SL. The hypoxia-responsive transcription factor EPAS1 is essential for catecholamine homeostasis and protection against heart failure during embryonic development. Genes Dev 1998; 12: 3320-3324.

30. Gruber M, Hu CJ, Johnson RS, Brown EJ, Keith B, Simon MC. Acute postnatal ablation of Hif-2alpha results in anemia. Proc Natl Acad Sci USA 2007; 104: 2301-2306.

31. Ovchinnikov DA, Deng JM, Ogunrinu G, Behringer RR. Col2a1-directed expression of Cre recombinase in differentiating chondrocytes in transgenic mice. Genesis 2000; 26: 145-146.

32. Kleemann RU, Krocker D, Cedraro A, Tuischer J, Duda GN. Altered cartilage mechanics and histology in knee osteoarthritis: relation to clinical assessment (ICRS Grade) Osteoarthritis Cartilage 2005; 13: 958-963.
33. Mankin HJ, Dorfman H, Lippiello L, Zarins A. Biochemical and metabolic abnormalities in articular cartilage from osteo-arthritic human hips.ll. Correlation of morphology with biochemical and metabolic data. J Bone Joint Surg Am 1971; 53: 523-537.

34. Kim JS, Ryoo ZY, Chun JS. Cytokine-like 1 (Cyt11) regulates the chondrogenesis of mesenchymal cells. J Biol Chem 2007; 282: 29359-29367.

35. Kim SJ, Ju JW, Oh CD, Yoon YM, Song WK, Kim JH et al. ERK-1/2 and p38 kinase oppositely regulate nitric oxide-induced apoptosis of chondrocytes in association with $\mathrm{p53}$, caspase-3, and differentiation status. J Biol Chem 2002; 277: 1332-1339.

\section{(c)}

This work is licensed under the Creative Commons

Attribution-NonCommercial-No Derivative Works 3.0

Unported License. To view a copy of this license, visit http:// creativecommons.org/licenses/by-nc-nd/3.0

Supplementary Information accompanies the paper on Cell Death and Differentiation website (http://www.nature.com/cdd) 